\title{
INCREMENTAL VALIDITY AND INDIRECT EFFECT OF ETHICAL DEVELOPMENT ON WORK PERFORMANCE
}

Yih-teen Lee

IESE Business School

Alfred Stettler \& John Antonakis

University of Lausanne

\section{Address correspondence to}

John Antonakis

Internef 618

University of Lausanne

Lausanne 1015, Switzerland

e-mail: john.antonakis@unil.ch 


\section{INCREMENTAL VALIDITY AND INDIRECT EFFECT OF ETHICAL DEVELOPMENT ON WORK PERFORMANCE}

We modeled work performance as outcomes of individual-differences mediated by technical performance. Beyond the "usual suspects" (e.g., general mental ability, and personality), we also measured the ethical development of participants $(n=460)$. We surmised that ethical development--which has not been extensively studied as a predictor of work performance while controlling for established predictors--captures unique variance in both technical and work performance. Results demonstrated incremental validity for ethical development in predicting technical performance, which in turn predicted work performance. The indirect effect of ethical development was significant too. Our results highlight the importance of process models of performance, which include proximal as well as distal individual differences.

Keywords: ethical development; morals and values; DIT; general mental ability; personality; technical performance; work performance; process model. 
First copyedit complete.

\section{Introduction}

Individual-differences such as general mental ability (GMA) and personality have important impacts on performance in education and work settings (Barrick \& Mount, 1991; Kuncel, Ones, \& Sackett, 2010; O’Connor \& Paunonen, 2007; Schmidt \& Hunter 1998). Scholars have recently begun to investigate variables that go beyond established predictors (e.g., Leeson, Ciarrochi, \& Heaven, 2008). One factor that has not been studied extensively is ethical development.

Although gaining attention (Gatewood \& Carroll, 1991; Vitell \& Davis 1990), little is known about how ethical development affects technical and work performance. Also, to our knowledge, no study has examined whether ethical development predicts performance while controlling for GMA and personality. Failure to include known predictors of performance as controls may engender omitted variable bias (Antonakis, Bendahan, Jacquart, \& Lalive, 2010); that is, model coefficients will be incorrectly estimated to the extent that the omitted variables correlate with the outcome and the predictors. Our objective was, therefore, to elucidate the incremental effect of ethical development.

Furthermore, given that variables, whether based on values, preferences or abilities might be more distally related to performance outcomes--particularly in highlytechnical domains where explicitly-taught principles are required for effective performance--we theorized that the effect of the individual differences would indirectly predict work performance. We theorized that technical performance, as a proximal predictor, mediates the effects between distal predictors (e.g., individual differences) and work performance (Hunter, 1986; Schmidt \& Hunter, 2004). We explain our theory next. 


\section{A process model of performance outcomes}

We propose a process model of distal traits (e.g., personality) that predict performance on proximal outcomes (technical performance), which in turn predicts work performance. We suggest too that ethical development should be considered as a distal trait in a more complete model of individual differences.

Ethical development refers to level of cognitive moral reasoning (Rest, 1986). According Kohlberg's (1981) stage developmental theory, individuals vary on their degree of principled ethical reasoning regarding how they conceptualize societal relationships and view justice. Those high on ethical development are likely to exhibit dutifulness and self-discipline, which should translate into a high work ethic and contribute to academic and work performance (particularly in contexts where professional principles and practices that are considered to be normatively good for society are at play). In fact, ethical development and academic performance correlate positively (Cheung, 1999). In a meta-analysis of the Defining Issues Test (DIT), which we used in our study, ethical development was significantly correlated with level of education completion, thus suggesting better knowledge acquisition for those who are higher on moral reasoning (Rest, Thoma, Narvaez, \& Bebeau, 1997). Those who are higher on ethical development should be more conscientious and dutiful--in a performance-based way that is not captured by self-reported personality tests--which should predict higher technical performance. Also, because ethical development is more in the realm of preferences it should be relatively independent of GMA.

H1: Ethical development positively predicts technical performance (beyond the effects of personality and GMA). 
Numerous studies have documented that technical performance (i.e., job knowledge) is critical in determining work performance (Dye, Reck, \& Murphy, 1993; Hunter, 1986; Schmidt \& Hunter, 2004), particularly in highly complex domains (Tan \& Libby, 1997). Without relevant knowledge, it is unlikely that one can perform effectively in a work setting. Important to note here is that knowledge obtained in courses that certify auditors is directly transferable to work situations; thus, although we measured academic performance (grades), variance in this performance measure should predict technical jobrelated skills. In any case, academic performance is a valid predictor of work performance (Roth, BeVier, Switzer, \& Schippmann, 1996). Hence, we surmise that technical performance in an academic setting, which should reflect job knowledge necessary to succeed, should be positively linked to work performance.

\section{H2: Technical performance positively predicts work performance.}

As noted by Schmidt and Hunter (2004, p. 170), "the major mediating link between GMA and job performance is job knowledge" (see also Hunton, Wier, \& Stone 2000; Libby \& Luft, 1993). It is important to note that the specified exogenous variables (e.g., personality, ethical development) should correlate both with the endogenous variables (i.e., technical performance) and with the dependent variable (i.e., work performance) for mediation to be shown. In fact, the estimator we used emulates what two-stage least squares does, which requires that the independent variables overlap both with the mediator and the dependent variable (Antonakis et al., 2010). As noted previously, ability and personality predict work performance directly (Schmidt \& Hunter, 1998; Barrick \& Mount, 1991; Kuncel, Hezlett, \& Ones, 2004); they also predict technical performance. Building on this previous logic, we argue that technical 
performance mediates the relationship between ethical development and work performance (thus, ethical development should predict work performance too for the mediation hypothesis to hold).

Studies have suggested that ethical development reflects individuals' orientation to comply with established norms and professional standards (Ponemon \& Gabhart, 1994). Such compliance may contribute to one's learning and acquisition of technical knowledge. As a result, ethical development is positively related to professional commitment, especially in highly codified professions such as auditing (Jeffrey, Weatherholt, \& Lo, 1996; see also Shaub, Finn \& Munter, 1993). Theoretically, individuals with a higher level of ethical development should have a clearer understanding of the importance of their work and its ethical implications to social systems. Such a sense of duty and responsibility will make individuals commit to a stronger work ethic and they should therefore have higher work performance. Furthermore, auditors with higher level of ethical development tend to internalize compliance with accounting standards and codes of conduct, which should contribute to higher work performance (Lampe \& Finn, 1992). For example, pharmacists' ethical development can explain a significant amount of the variance in their clinical performance (Latif, 2000). Also, supervisors will more likely perceive ethical and professionally committed individuals as better performer (Mortensen, Smith, \& Cavanagh, 1989).

H3: Technical performance mediates the relationship between ethical development and work performance.

\section{Method}




\subsection{Sample and procedures}

Our sample consisted of Swiss French and Swiss German trainee auditors working mainly for multinational auditing firms in Switzerland during the period when they attended a training program organized by the Swiss Academy of Auditing. This program is part of the process to obtain the qualification of a certified auditor. All data were collected on a voluntary and confidential basis. Of 620 participants of the program, 460 (74\%) accepted to participate. The average age of the participants was 27.58 years, SD $=$ 3.08 (where the mean working age in Switzerland is 42.55 years, SD $=14.08$, Swiss Household Panel, 2008); thus, our sample better reflects working population characteristics than do typical student samples that use much younger participants (i.e., 18-20 years).

We administered a GMA test as well as a demographic questionnaire during class time; participants completed the personality and ethical development measures during their free time and returned them to us either in person or by postal mail. Apart from individual differences measures, we obtained work performance measures on the trainee auditors completed by the trainees' supervisors, whom we contacted directly; we also obtained measures of trainees' technical performance (i.e., grades) from the program administrators of the Academy. Because we collected data at various times, with different instruments and from different sources, we avoided, to a large extent, problems associated with common method bias (Antonakis et al., 2010).

\subsection{Measures}

\subsubsection{General mental ability}


For the French-speaking participants, we used the French version of the 50-item Wonderlic Personnel Test (WPT Form A) to assess GMA of participants. The Wonderlic Personnel Test is a widely used mental ability test and its validity has been established by previous research either for its original English version (e.g., Furnham \& ChamorroPremuzic, 2004) or the French version (e.g., Rousseau \& McKelvie, 2000). Because there is no German version of the Wonderlic Personnel Test, we used ZVT (Der ZahlenVerbindungs-Test; Oswald \& Roth, 1987) and WST (Wortschatztest; Schmidt \& Metzler, 1992) to measure the GMA of the German-speaking participants. These tests are, respectively, measures of fluid (cf. Vernon, 1993) and crystallized (verbal) ability (cf. Merten, 2005). We standardized scores within the two language groups and pooled the data.

\subsubsection{Ethical development}

We used the DIT1 (Rest, 1986) to measure ethical development. We used a French version of DIT1 (translated by A. Andronikof and L. Chudzik of University of Paris-Dauphine) and German version (translated by G. Lind of University of Konstanz), with minor modifications according to the characteristics of the specific Swiss context. DIT1 consists of six vignettes, requiring respondents to take a position and rate the courses of actions for those decisions. We use the p-score (the proportion of items that reflect the highest level of ethical development) as an indicator performance on the test as is conventionally done (cf. Sweeney \& Fisher, 1998).

\subsubsection{Personality}

We measured the personality (i.e., Neuroticism, Openness to Experience, Conscientiousness, Agreeableness, and Extraversion) of participants using the official 
French and German NEO revised personality inventory, NEO PI-R (Costa \& McCrae, 1992). We also controlled for general self-efficacy (Chen, Gully, \& Eden, 2001), given that this disposition is strongly related to work outcomes (Stajkovic \& Luthans, 1998); furthermore its inclusion is justified given that self-efficacy might not be adequately captured by the big five inventory (Caprara, Barbaranelli, Pastorelli, \& Cervone, 2004).

\subsubsection{Technical Performance}

We used the grades which the participants obtained in the end of the theoretical part of the training program to measure technical performance. Because the French and German group of participants were taught by different experts that might use a different grading scale, we first standardized within language group before pooling the data.

\subsubsection{Work performance}

We based the work-performance measure on the six dimensions of Day and Silverman's (1989, pp. 28-29) scale, which assessed the work performance of accountants. The work-performance scale included the following items: "demonstrates strong potential to succeed in the auditing profession," "masters the technical aspect of his/her work," "accomplishes his/her task within deadlines," "earns the confidence, respect, and cooperation of clients," "shows a positive and professional attitude when working with colleagues at all levels," "is willing to work extra hours to accomplish his/her assigned tasks" $(\alpha=.81)$. We sent this measure to the supervisors of the trainee auditors by postal mail; they rated each item on a 1 to 7 Likert-type scale and returned the questionnaire to us by post.

\subsubsection{Additional control variables}


We included gender (male $=1$, otherwise 0 ) and the language region $($ French $=1$, otherwise 0 ) of residence of the respondent as control variables. We also included age and years of work experience in auditing so as to adjust for the chronological maturity and acquired practical experience of participants. Finally, because we gathered data from (a) four multinational auditing firms and (b) some smaller firms, we controlled for these fixed effects using five groups (i.e., the four big firms and one group reflecting non-big four firms); controlling for these firm-level effects is important because companies may have different selection and training policies which may correlate with individual differences and the outcomes. We thus accounted for any unobserved effects due to firms that were not explicitly measured (Antonakis et al., 2010).

\subsection{Estimation strategy}

We estimated the following system of equations (see Figure 1):

TechP $=\gamma_{0}+\gamma_{1}$ Ethics $+\gamma_{2}$ GMA $+\gamma_{3} \mathrm{~N}+\gamma_{4} \mathrm{E}+\gamma_{5} \mathrm{O}+\gamma_{6} \mathrm{~A}+\gamma_{7} \mathrm{C}+$

$$
\gamma_{8} \mathrm{SE}+\gamma_{9} \text { Male }+\gamma_{10} \mathrm{Age}+\gamma_{11} \mathrm{EXP}+\gamma_{12} \mathrm{D}_{\text {French }}+\sum_{k=2}^{5} \lambda_{k} \text { Firm }_{k}+u
$$

Eq. 1

$$
\begin{aligned}
\mathrm{WP}= & \beta_{0}+\beta_{1} \text { TechP }+\beta_{2} \text { Male }+\beta_{3} \text { Age }+\beta_{4} \mathrm{EXP}+\beta_{5} \mathrm{D}_{\text {French }} \\
& +\sum_{k=2}^{5} \omega_{k} \text { Firm }_{k}+\varepsilon
\end{aligned}
$$

Where TechP $=$ technical performance, Ethics $=$ ethical development, GMA = general mental ability, $\mathrm{N}=$ Neuroticism, $\mathrm{E}=$ Extraversion, $\mathrm{O}=$ Openness, $\mathrm{A}=$ Agreeableness, $\mathrm{C}=$ Conscientiousness, $\mathrm{SE}=$ self efficacy, Male $=$ gender dummy, Age $=$ age, $\mathrm{EXP}=$ auditing work experience, $\mathrm{D}_{\text {French }}=$ dummy for auditors from the Frenchspeaking region, Firm is firm-level dummy variables $(k-1$ dummies $)$, and $\mathrm{WP}=$ work 
performance. As with the two-stage least squares estimator we allowed the disturbances ( $\varepsilon$ and $u$ ) of the two equations to correlate.

\section{[Insert Figure 1 here]}

Note that having stable individual differences as exogenous sources of variance ensures that estimates between technical performance and work performance are not confounded and can be interpreted causally (Antonakis et al., 2010). That is, only the portion of the variance shared by the individual differences and technical performance with work performance is used to estimate the effect technical performance on work performance, which allows for unconfounded interpretation (this estimation procedure is precisely what the two-stage least squares accomplishes when estimating causal models of this nature, see Gennetian, Magnuson, Morris, 2008). This technique is useful because for example, supervisors who have knowledge of participants' grades may rate them higher on performance or may have selected them on their grades. This simultaneity can be corrected with our modeling procedure, where the disturbances of the two endogenous variables is estimated so as to emulate the two-stage least squares estimator and "lock-in" the causal pathway in one direction (Antonakis et al., 2010).

We estimated the system of equations (i.e., a Structural Equation Model) using Mplus's (Version 6) robust maximum likelihood estimator, which also implements the Expectation Maximization (EM) algorithm (Dempster, Laird, \& Rubin, 1977); this estimator allows for the analysis of the full sample, even if an observation is missing a value on a particular variable (i.e., this avoids using listwise deletion, which can reduce the sample size and inflate standard errors). We created indexes of unidimensional scales that had multiple items. We also specified the measurement error in the estimation 
procedure, which can affect consistency of estimates in the variables measured with error (i.e., GMA, the "big five", self-efficacy) as well as in correlated covariates. We modeled latent variables and used the formula provided by Bollen (1989) to constrained the residual $\varepsilon$ of latent variable $\xi$ to $(1-\rho) * \operatorname{var}_{x}$, where $\rho$ is an estimate of the reliability and $\operatorname{var}_{x}$ is the observed variance of the variable concerned.

\section{Results}

Refer to descriptive statistics and correlations among study variables in Table 1.

\section{[Insert Table 1 here]}

The model we estimated indicated very good fit: robust $\chi^{2}(7)=3.83, p=.80$; that is, the overidentifying constraints we imposed on this mediational model could not be rejected by the data suggesting full mediation. To demonstrate that ethical development predicts technical performance and work performance beyond GMA and personality (i.e., the hierarchical test of first adding GMA and personality in Step 1, and then adding ethical development in Step 2), we tested a second model in which we constrained the coefficient of ethical development on technical performance to zero. Given that we used a robust chi-square test for the models, we used a nested log-likelihood difference test between the two models. The constrained model (without ethical development) was significantly worse than the unconstrained model (with ethical development): $\chi^{2}(1)=$ $9.31, \mathrm{p}<.01$. Thus, there is a significant effect of ethical development on technical performance beyond GMA and personality (standardized $\beta=.26, p<.001$ ) supporting H1. Note, the change in $\mathrm{R}^{2}$ was .06 when adding ethical development to the model. Refer to Figure 1 for final results. 
As for the control variables, GMA and self efficacy were significantly related to technical performance. Regarding personality, we obtained some unexpected findings: Neuroticism positively predicted technical performance, and Openness was negatively related to technical performance. Contrary to previous findings, Conscientiousness was not significantly related to technical performance, though self-efficacy was. In support of $\mathrm{H} 2$, technical performance was positively related to supervisor work performance, standardized $\beta=.59, \mathrm{p}<.05$

We used the delta method procedure in Mplus (using the Sobel test) to test the indirect effects of the individual differences on work performance. Ethical development indirectly predicted work performance (standardized effect $=.16, p<.05$ ), supporting H3 (and also showing an incremental indirect effect). We also found indirect effects for GMA (standardized effect $=.11, p<.05)$, Neuroticism $($ standardized effect $=.22, p$ $<.05$ ), and Openness (standardized effect $=-.18, p<.05$ ); self-efficacy just failed to reach significance $($ standardized effect $=.16, p=.08)$.

\section{Discussion}

The present study is, to our knowledge, the first examining the effect of ethical development on technical and work performance while controlling for established predictors as well as the fixed effects of firms. Another strength of our study is that we used two samples from two language regions (cultures), which enhances the generalizability of the findings. Substantively, our study's contributions are twofold: (a) we contribute to the individual-differences literature in demonstrating the importance of ethical development for predicting technical and work performance; (b) our findings echo 
previous research (e.g., Hunton et al. 2000; Libby \& Luft 1993; Schmidt \& Hunter, 2004) regarding the mediating role of knowledge in predicting work performance.

Beyond the effects of well-established individual-difference factors such as GMA and big five personality, we found ethical development to be positively related to technical performance. These results could have particular importance in the auditing profession after the scandals of late; auditing educators have taken measures to reinforce the ethical component in their education programs (e.g., Earley \& Kelly, 2004). Beyond the contribution to technical performance we assume that higher ethical development will lead to ethical job-related decision-making, as previous studies suggest (Abdolmohammadi, \& Sultan, 2002). As an understudied individual-difference factor, ethical development should receive more attention for its contribution to critical behavioral outcomes and work performance, and should be considered in business-school educational programs.

Interestingly (and counter-intuitively), Neuroticism had a positive relationship with technical performance; there is evidence to suggest that individual with high levels of negative affectivity (or in being in a negative mood) perform better on difficult and complex tasks (reminiscent of the tasks done by auditors) than do individuals who are low on negative affectivity (Fortunato \& Williams, 2002; see also Sanna, Turley, \& Mark, 1996). Perhaps neuroticism stimulates a "healthy" level of anxiety, which is a natural psychological mechanism for human beings to strive and survive in challenging circumstances (Rosen, 2008). In the case of our sample, perhaps this anxiety translated to more effort in succeeding (cf. Sanna et al., 1996). Interesting too was the negative effect of Openness; again, it is possible that the nature of our sample was such that a more 
prosaic and conservative disposition would make for success in a highly rules-based environment, where one cannot demonstrate too much creativity and originality. Furthermore, Conscientiousness was unrelated to technical performance because selfefficacy's effects eclipsed those of Conscientiousness (Conscientiousness was only significant, standardized $\beta=0.19, p<.05$, when we removed self-efficacy from the model).

Finally, our study confirmed that technical performance is critical in directly predicting work performance and in mediating the effects of the individual differences. As discussed before, the auditing profession may require the mastering of highly sophisticated accounting and auditing rules, standards, and procedures, which is usually developed in an academic setting. Hence, technical performance in an academic setting is a good proxy of technical work performance

\subsection{Limitations and Future Research}

Although we provided some insights into predicting work performance, our results must be viewed in light of some limitations. Despite the fact that we collected the data from several sources at different times, the study was not longitudinal in nature. That is, it is not possible for us to claim clear-cut predictive validity for the individual differences (however, given that we have exogenous variables, we have confidence in the causal concurrent validity implications of our findings). Future research should consider collecting longitudinal data to establish the predictive relationships among the variables. Furthermore, our estimates should be considered lower-bound, given the probable rangerestriction in the observed variance of the measures. 
Important aspects to consider for future empirical work are contextual effects, including the impact of task complexity, hierarchical level, company size, national culture, laws, and other contextual factors (Liden \& Antonakis, 2009). Finally, it would be interesting for future research to gather behavioral measures of ethical performance. Although inroads are being made in this area, there is still insufficient research to show how tests of ethical reasoning predict actual ethical outcomes.

\section{Conclusion}

The present research sheds light on the importance of ethical development and technical performance on work performance. Importantly, ethical development predicted technical performance beyond established individual-differences measures like GMA and the big five personality factors. In terms of the individual-difference findings, this research has important implications for personnel selectors. We hope our findings will pave the way for further work on ethical development and process modeling in consequential performance environments. 


\section{REFERENCES}

Abdolmohammadi, M., \& Sultan, J. (2002). Ethical reasoning and the use of insider information in stock trading. Journal of Business Ethics, 37, 165-173.

Antonakis, J., Bendahan, S., Jacquart, P., \& Lalive, R. (2010). On making causal claims: A review and recommendations. The Leadership Quarterly, 21(6), 1086-1120.

Barrick, M. R., \& Mount, M. K. (1991). The big five personality dimensions and job performance: a meta-analysis. Personnel Psychology 44, 1-26.

Bollen, K. A. (1989). Structural equations with latent variables. New York: Wiley.

Caprara, G. V., Barbaranelli, C., Pastorelli, C., \& Cervone, D. (2004). The contribution of self-efficacy beliefs to psychosocial outcomes in adolescence: predicting beyond global dispositional tendencies. Personality and Individual Differences, 37, 751-763.

Chen, G., Gully, S. M., \& Eden, D. (2001). Validation of a new general self-efficacy scale. Organizational Research Methods, 4, 62-83.

Cheung, C.-K. (1999). Ethical judgment and ethical reasoning on business issues: a crosslag model for university students in Hong Kong. College Student Journal, 33, 515531.

Costa, P. T., \& McCrae, R. R. (1992). NEO-PI-R. Inventaire de personnalité-révisé. Paris: Les Editions du Centre de Psychologies Appliquée.

Day, D. V., \& Silverman, S. B. (1989). Personality and job performance: evidence of incremental validity. Personnel Psychology 42, 25-36.

Dempster, A.P., Laird, N.M., \& Rubin, D.B. (1977). Maximum likelihood from incomplete data via the EM algorithm. Journal of the Royal Statistical Society, Series B (Methodological) 39, 1-38. 
Dye, D. A., Reck, M., \& Murphy, M. A. (1993). The validity of job knowledge measures. International Journal of Selection and Assessment, 1, 153-157.

Earley, C. E., \& Kelly, P. T. (2004). A note on ethics educational interventions in an undergraduate auditing course: Is there an "Enron Effect"? Issues in Accounting Education, 19, 53-71.

Fortunato, V. J., \& Williams, K. J. (2002). The moderating effects of dispositional affectivity on performance and task attitudes in a goal-setting context. Journal of Applied Social Psychology, 32, 2321-2353.

Furnham, A., \& Chamorro-Premuzic, T. (2004). Personality and intelligence as predictors of statistics examination grades. Personality and Individual Differences 37: 943955.

Gatewood, R. D., \& Carroll, A. B. (1991). Assessment of ethical performance of organization members: A conceptual framework. Academy of Management Review, $16,667-690$

Gennetian, L. A., Magnuson, K., \& Morris, P. A. (2008). From statistical associations to causation: What developmentalists can learn from instrumental variables techniques coupled with experimental data. Developmental Psychology, 44, 381-394.

Hunter, J. E. (1986). Cognitive ability, cognitive aptitudes, job knowledge, and job performance. Journal of Vocational Behavior, 29, 340-362.

Hunton, J. E., Wier, B., \& Stone, D. N. (2000). Succeeding in managerial accounting. Part 2: a structural equations analysis. Accounting, Organizations and Society, 25, 751-762. 
Jeffrey, C., Weatherholt, N., \& Lo, S. (1996). Ethical development, professional commitment and rule observance attitudes: A study of auditors in Taiwan. The International Journal of Accounting, 31(3), 365-379.

Kohlberg, L. (1981). The Philosophy of Moral Development: Moral Stages and the Idea of Justice. San Francisco: Harper \& Row.

Kuncel, N. R., Hezlett, S. A., \& Ones, D. S. (2004). Academic performance, career potential, creativity, and job performance: Can one construct predict them all? Journal of Personality \& Social Psychology, 86, 148-151.

Kuncel, N. R., Ones, D. S., \& Sackett, P. R. (2010). Individual differences as predictors of work, educational, and broad life outcomes. Personality and Individual Differences, 49, 331-336.

Lampe, J.C. \& Finn, D.W. (1992). A model of auditors' ethical decision processes, Auditing: A Journal of Practice and Theory, 11, (Supplement): 33-59.

Latif, D. A. (2000). The link between moral reasoning scores, social desirability, and patient care performance scores: Empirical evidence from the retail pharmacy setting. Journal of Business Ethics, 25(3), 255-269.

Leeson, P., Ciarrochi, J., \& Heaven, P. C. L. (2008). Cognitive ability, personality, and academic performance in adolescence. Personality and Individual Differences, 45, 630-635.

Libby, R., \& Luft, J. (1993). Determinants of judgment performance in accounting settings: Ability, knowledge, motivation, and environment. Accounting, Organizations and Society, 18, 425-450. 
Liden, R. C., \& Antonakis, J. (2009). Considering context in psychological leadership research. Human Relations, 62(11), 1-18.

Merten, T. (2005). Factor structure of the Hooper Visual Organization Test: a crosscultural replication and extension. Archives of Clinical Neuropsychology, 20, 123128.

Mortensen, R. A., Smith, J. E., \& Cavanagh, G. F. (1989). The importance of ethics to job performance: An empirical investigation of managers' perceptions. Journal of Business Ethics, 8(4), 253-260.

Oswald, W. D., \& Roth, E. (1987). Der Zahlen-Verbindungs-Test (2. überarbeitete und erweiterte Auflage). Gottingen: Hogrefe.

Ponemon, L., \& Gabhart, D. R. (1990). Auditor independence judgments: A cognitive developmental model and experimental evidence. Contemporary Accounting Research, 7, 221-251.

Rest, J. R. (1986). Manual for the Defining Issues Test, 3rd ed. Minneapolis, MN: University of Minnesota.

Rest, J., Thoma, S. J., Narvaez, D., \& Bebeau, M. J. (1997). Alchemy and beyond: indexing the Defining Issues Test. Journal of Educational Psychology, 89, 498-507.

Rosen, R. H. (2008). Just enough anxiety: the hidden driver of business success. New York: Portfolio.

Roth, P. L., BeVier, C. A., Switzer, F. S., \& Schippmann, J. (1996). Meta-analyzing the relationship between grades and job performance. Journal of Applied Psychology $81,548-556$ 
Rousseau, F. L., \& McKelvie, S. J. (2000). Effects of feedback on intelligence test performance. The Journal of Psychology, 134, 5-14.

Sanna, L. J., Turley, K. J., \& Mark, M. M. (1996). Expected evaluation, goals, and performance: Mood as input. Personality and Social Psychology Bulletin, 22, $323-335$.

Shaub, M. K., Finn, D. W., \& Munter, P. (1993). The effects of auditors' ethical orientation on commitment and ethical sensitivity, Behavioral Research in Accounting, 5, 145-169.

Schmidt, F. L., \& Hunter, J. E. (1998). The validity and utility of selection methods in personnel psychology: practical and theoretical implications of 85 years of research findings. Psychological Bulletin. 12, 262-274.

Schmidt, F. L., \& Hunter, J. (2004). General mental ability in the world of work: Occupational attainment and job performance. Journal of Personality and Social Psychology, 86: 162-173.

Schmidt, K. H., \& Metzler, P. (1992). Wortschatztest (WST). Weinheim: Beltz.

Stajkovic, A. D., \& Luthans, F. (1998). Self-efficacy and work-related performance: A meta-Analysis. Psychological Bulletin, 124, 240-261.

Sweeney, J., \& Fisher, D. (1998). An examination of the validity of a new measure of moral judgement. Behavioral Research in Accounting, 10, 138-158.

Swiss Household Panel (2008). http://www.swisspanel.ch.

Tan, H. T., \& Libby, R. (1997). Tacit managerial versus technical knowledge as determinants of audit expertise in the field. Journal of Accounting Research, 35, 97113. 
Vernon, P. A. (1993). Der-Zahlen-Verbindungs-test and other trail-making correlates of general intelligence. Personality and Individual Differences, 14, 35-40.

Vitell, S. J., \& Davis, D. L. (1990). The relationship between ethics and job satisfaction: An empirical investigation. Journal of Business Ethics, 9, 489-494. 
Table 1. Descriptive Statistics and Correlations among Study Variables

\begin{tabular}{|c|c|c|c|c|c|c|c|c|c|c|c|c|c|c|c|c|}
\hline & & Mean & $S D$ & 1 & 2 & 3 & 4 & 5 & 6 & 7 & 8 & 9 & 10 & 11 & 12 & 13 \\
\hline 1 & Neuroticism & 43.71 & 9.28 & & & & & & & & & & & & & \\
\hline 2 & Extraversion & 55.02 & 10.25 & -.47 & & & & & & & & & & & & \\
\hline 3 & Openness & 50.51 & 8.61 & -.04 & .34 & & & & & & & & & & & \\
\hline 4 & Agreeable. & 47.79 & 9.58 & .02 & -.12 & .05 & & & & & & & & & & \\
\hline 5 & Consc. & 57.07 & 8.24 & -.43 & .35 & -.05 & .01 & & & & & & & & & \\
\hline 6 & Self Efficacy & 4.00 & .46 & -.55 & .39 & .17 & -.21 & .45 & & & & & & & & \\
\hline 7 & GMA & -.01 & .83 & .02 & .16 & .16 & .01 & -.05 & .10 & & & & & & & \\
\hline 8 & Ethical Dev. & 40.49 & 12.06 & .11 & -.09 & .21 & .02 & -.05 & .01 & .14 & & & & & & \\
\hline 9 & Tech. Perf. & .00 & .99 & .11 & .06 & -.12 & -.01 & .17 & .17 & .24 & .24 & & & & & \\
\hline 10 & Work Perf. & 6.02 & .66 & .05 & .04 & -.06 & -.03 & .09 & .12 & .12 & .16 & .21 & & & & \\
\hline 11 & French & .23 & .42 & .29 & -.07 & -.14 & .09 & -.15 & -.29 & -.01 & .10 & -.02 & -.06 & & & \\
\hline 12 & Male & .71 & .46 & .04 & -.13 & -.18 & .12 & .00 & .01 & .09 & -.09 & .10 & -.04 & .01 & & \\
\hline 13 & Age & 27.58 & 3.08 & -.08 & -.01 & -.02 & -.04 & .01 & .04 & -.17 & -.01 & -.09 & -.02 & -.17 & -.01 & \\
\hline 14 & Audit Exp. & 1.67 & .79 & .04 & -.10 & -.04 & .07 & .04 & -.07 & -.12 & -.05 & -.04 & .01 & .04 & .08 & .16 \\
\hline
\end{tabular}

Note: $\mathrm{N}=460$; Estimation is with the EM algorithm. For $\mathrm{r}>|.10|, \mathrm{p}<.05 ; \mathrm{r}>|.13|, \mathrm{p}<.01 ; \mathrm{r}>|.16|, \mathrm{p}<.001$ 


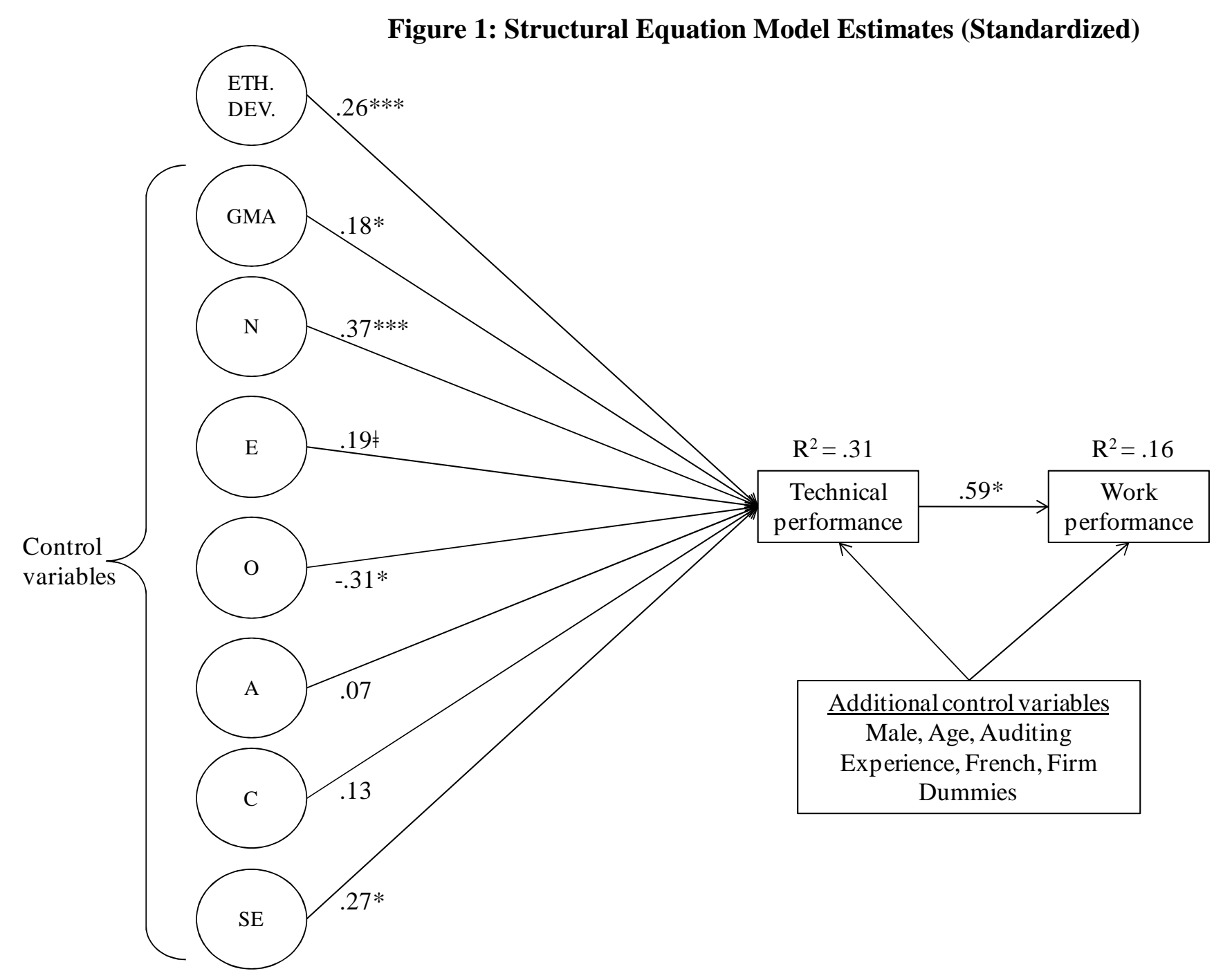


$* * * \mathrm{p}<.001, * * \mathrm{p}<.01, * \mathrm{p}<.05, \neq \mathrm{p}<.10 ; \mathrm{N}=460$. Firm fixed effect contribution to $\mathrm{R}^{2}$ is .04 (work performance) and .03 (technical performance). Eth. Dev. = ethical development, GMA = general mental ability, $\mathrm{N}=$ Neuroticism, $\mathrm{E}=\mathrm{Extraversion}, \mathrm{O}=\mathrm{Openness,} \mathrm{A}$ = Agreeableness, $\mathrm{C}=$ Conscientiousness, $\mathrm{SE}=$ self efficacy. 